\title{
ПРИНЦИП ДИСПОЗИТИВНОСТИ И ПРОЦЕССУАЛЬНАЯ АКТИВНОСТЬ СУДА В ГРАЖДАНСКОМ ПРОЦЕССЕ
}

\section{THE PRINCIPLE OF DISPOSITIVITY AND PROCEDURAL ACTIVITY OF THE COURT IN CIVIL PROCEEDINGS}

\section{Petrozhitskiy}

Summary. This article examines the essence of the principle of dispositivity and the procedural activity of the court, using the example of court decisions made. It is noted that there is no structural element with the name "principles"in the Civil Procedure Code of the Russian Federation. This negatively affects the implementation of the principles of civil procedure in law enforcement practice. In this connection, it is proposed to introduce separate articles into the chapter of the Civil Procedure Code of the Russian Federation "Basic provisions", systematizing and directly fixing the concept and composition of the principles of civil procedural law.

Keywords: civil procedure, court, dispositivity, activity of the court, code.
Петрожицкий Виталий Игоревчч

Санкт-Петербургский государственный архитектурно-строительный университет petrozhitskiy97@mail.ru

Аннотация. В настоящей статье рассмотрена сущность принципа диспозитивности и процессуальная активность суда, на примере вынесенных судебных решений. Отмечено, что в ГПК РФ отсутствует структурный элемент с названием «принципы». Это негативно влияет на реализацию принципов гражданского процесса в правоприменительной практике. В связи с чем предложено внесение в главу ГПК РФ «0сновные положения» отдельных статей, систематизирующих и прямо закрепляющих понятие и состав принципов гражданского процессуального права.

Ключевые слова: гражданский процесс, суд, диспозитивность, активность суда, кодекс.

Но системно и последовательно изложенных принципов гражданского процессуального права нет.

Вместе с тем, предмет исследования настоящей статьи составляют не общие положения гражданского процессуального права, а принцип диспозитивности и процессуальная активность суда в гражданском процессе, поскольку данная тематика является очень актуальной в настоящее время.

Так, принцип диспозитивности следует обозначить в качестве одного из основополагающих принципов гражданского процесса. Его содержание предполагает свободу субъектов в части распоряжения всем принадлежащим им объемом материальных и процессуальных прав. В частности, участники процесса могут иметь своей целью:

- возникновение гражданского процесса (путем реализации своего права на обращение с исковым заявлением в суд),

- развитие гражданского процесса (подавая апелляционную жалобу),

- прекращение гражданского процесса (путем заключения мирового соглашения). 
Таким образом, можно говорить о том, что принцип диспозитивности является движущим началом в гражданском процессе.

Суть принципа диспозитивности находит выражение в определении предмета, основании иска, их применении, увеличении или уменьшении объема требований, отказе от иска. Суд, в рамках своей процессуальной активности, проводит проверку законности действий участников процесса, соблюдение их прав и интересов.

Диспозитивность в материальном праве раскрывается в том, что суд не правомочен удовлетворять не заявленные стороной требования.

Диспозитивность в процессуальном праве раскрывается: в ходатайствах стороны, заявлении об обеспечении иска, то есть там, где отсутствует распоряжение материальным правом.

Так, например, гражданское процессуальное законодательство предусматривает, что основанием для участия в деле третьих лиц является их материально-правовая заинтересованность в исходе дела, которая должна иметь непосредственное отношение к предмету первоначального инициированного спора. То есть третье лицо, руководствуясь принципом диспозитивности, может реализовать свое право на участие в конкретном гражданском деле, при условии, что есть заявленное третьим лицом самостоятельное требование и оно связано с предметом спора по первоначально заявленным требованиям. Из изложенного следует, что права и обязанности, на которые может повлиять судебный акт, вынесенный по результатам рассмотрения по существу и на которые ссылается податель такого ходатайства, должны усматриваться из предмета настоящего спора.

В свою очередь, при решении вопроса о допуске лица в процесс в качестве третьего лица судья анализирует: какой правовой интерес имеет данное лицо. И в данном случае здесь также можно проследить процессуальную активность суда. Поскольку если судебным актом к одной из сторон не порождаются, не изменяются или не прекращаются материальные права и обязанности, то оснований для вступления такого лица в дело нет, так как отсутствует предмет для судебной защиты.

Следовательно, основанием для отказа в удовлетворении ходатайства о вступлении в дело в качестве третьего лица, заявляющего самостоятельные требования относительно предмета спора, является отсутствие идентичных требований такого лица относитель- но объекта иска. При такой ситуации суд отмечает, что лицо вправе обратиться в суд с самостоятельным иском за рамками данного дела [2].

Ввиду различий между процессуальными статусами третьих лиц, указанных в ст. ст. 42 и 43 ГПК РФ, существенно отличаются основания для отказа к участию в деле в качестве третьего лица, не заявляющего самостоятельных требований относительно предмета спора. Из анализа императивных положений действующего законодательства, а также обширной судебной практики следует, что сам факт желания того или иного лица представить в материалы дела какие-либо доказательства или изложить свою правовую позицию не может безусловно свидетельствовать о наличии необходимых процессуальных оснований для участия такого лица в деле в качестве третьего лица.

Еще одним примером процессуальной активности суда в данной области можно назвать следующую ситуацию.

Собственник жилого помещения в многоквартирном доме обратился в районный суд с иском к жилищному кооперативу об определении доли истца в несении расходов по содержанию общего имущества.

В ходе рассмотрения гражданского дела судом отказано в удовлетворении ходатайства истца о привлечении городской администрации и жилищной инспекции к участию в деле в качестве третьих лиц, не заявляющих самостоятельных требований относительно предмета спора, поскольку при рассмотрении дела по существу судом не установлено, что судебный акт, принятый по результатам рассмотрения гражданского дела, окажет какое - либо влияние на их права и обязанности [3].

Однако, считаем необходимым также отметить, что на практике со стороны суда имеют место трудности применения принципа состязательности на стадии возбуждения гражданского дела. Это находит выражение в проявлении активности суда в части вынесения определений об оставлении исковых заявлений. Это ведет к созданию более благоприятных условий именно для истца.

Поэтому возникает необходимость исследования на доктринальном уровне вопроса о раскрытии особенностей действия принципа состязательности на отдельных стадиях гражданского судопроизводства. Вследствие чего игнорирование принципа состязательности на стадии возбуждения гражданского дела можно объяснить наличием объективных ошибок, когда суды используют инструмент оставления без движения 
исключительно для оттягивания во времени возбуждение гражданского дела в связи с большим объемом имеющихся в производстве дел [4].

В завершение сделаем вывод о том, что вся вышеуказанная по тексту настоящей статьи правоприменительная практика свидетельствует о недостатках в гражданском процессуальном законодательстве в части отсутствия закрепления отдельной главы, по- священной принципам гражданского процессуального права. Об этом мы также отмечали в начале настоящей статьи.

Полагаем, что успешному разрешению указанной нами правовой проблемы способствовало бы внесение в главу ГПК РФ «Основные положения» отдельных статей, таких, как: «Понятие и состав принципов гражданского процессуального права».

\section{ЛИТЕРАТУРА}

1. Гражданский процессуальный кодекс Российской Федерации от 14.11.2002 N138-Ф3 (ред. от 01.07.2021) // Собрание законодательства РФ. 2002. N46. Ст. 4532.

2. Апелляционное определение Московского городского суда от 04.04.2018 по делу N33-14814/2018 // СПС «Консультант Плюс».

3. Апелляционное определение Свердловского областного суда от 16.05 .2019 по делу N33-7992/2019 // СПС «Консультант Плюс».

4. Апелляционное определение Куменского районного суда Кировской области от 19 января 2018 г. по делу N11-1/2018 // СПС «Консультант Плюс».

( П Петрожицкий Виталий Игоревич ( petrozhitskiy97@mail.ru ).

Журнал «Современная наука: актуальные проблемы теории и практики»

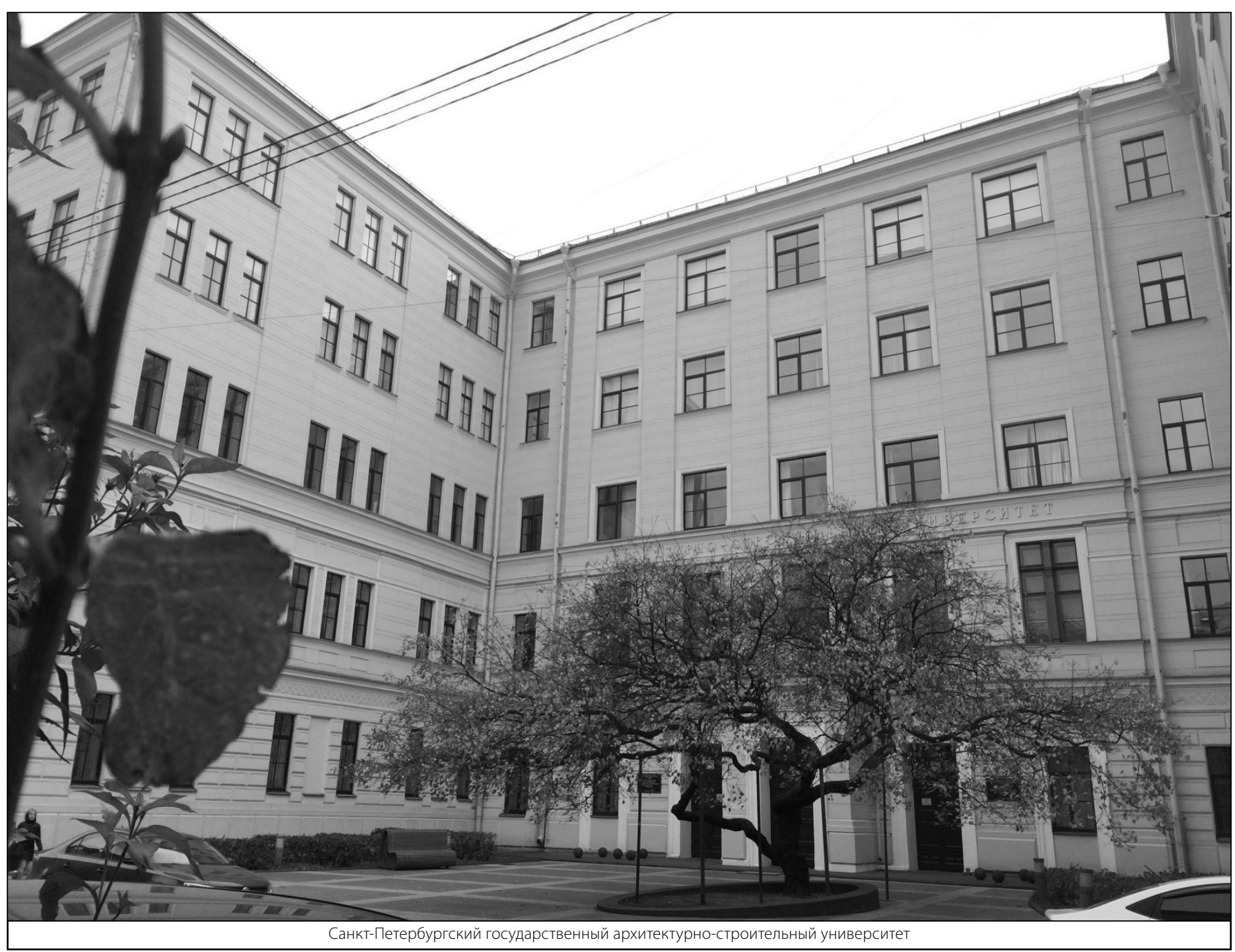

